\title{
A DISCIPLINA ESTUDO DE PROBLEMAS BRASILEIROS (EPB) NA UNIVERSIDADE FEDERAL DE VIÇOSA (UFV): EM FOCO O PROJETO EDUCACIONAL DO REGIME CIVIL-MILITAR PARA AS UNIVERSIDADES BRASILEIRAS ${ }^{1}$
}

\author{
Caio Corrêa Derossi ${ }^{*}$ \\ lattes.cnpq.br/2861629420221016 \\ Joana D'Arc Germano Hollerbach** \\ lattes.cnpq.br/5888935341011338 \\ Alvanize Valente Fernandes Ferenc ${ }^{* * *}$ \\ lattes.cnpq.br/3090603419576186
}

\begin{abstract}
Resumo: No contexto de acirramento das forças do regime civil-militar e da intensificação das estratégias de controle da população, em 1969 é criada a disciplina Estudo de Problemas Brasileiros (EPB), como matéria obrigatória. Direcionada ao ensino superior, era um instrumento ideológico do projeto educacional dos militares para o enfrentamento do movimento estudantil e das supostas ameaças do comunismo. Neste sentido, o presente artigo almeja contribuir para as discussões acerca do projeto de socialização dos interesses do regime militar nas universidades brasileiras. Por meio de pesquisa documental, contextualiza a EPB na Universidade Federal de Viçosa, Minas Gerais, a partir de fontes oficiais, como os catálogos de disciplinas da instituição, as atas e os documentos das reuniões de conselhos colegiados superiores do período de vigência da disciplina (1969-1993). No que tange à pesquisa documental, pode-se inferir, com base na organização dos cursos de EPB e na sua vigência, a sua plena aderência na instituição. Outro aspecto que merece destaque foi a realização dos cursos de EPB mesclando alunos do Colégio Universitário (COLUNI) e dos cursos
\end{abstract}

1 Este artigo é uma versão modificada do trabalhado apresentado como Comunicação Oral no X Congresso de Pesquisa e Ensino em História da Educação de Minas Gerais (COPEHE), realizado em Diamantina (MG), entre 6 e 08/05/2019.

* Mestrando em Educação na Universidade Federal de Viçosa (Brasil). Contato: derossi.caio@gmail.com.

** Doutora em Educação. Docente da Universidade Federal de Viçosa (Brasil). Contato: joana.germano@ufv.br.

*** Doutora em Educação. Docente na Universidade Federal de Viçosa (Brasil). Contato: avalenteferenc@gmail.com. 
de graduação e pós-graduação, mesmo que essa prática não tivesse sido prescrita na lei, o que nos leva a concluir que houve empenho na transmissão da mensagem dos governos militares aos estudantes brasileiros, em detrimento de um esforço didático-pedagógico, a supor pelas diferenças entre os níveis de escolarização contemplados.

Palavras-chave: Estudo de Problemas Brasileiros (EPB); Regime civil-militar; Doutrina de Segurança Nacional (DSN); Universidade Federal de Viçosa (UFV).

\title{
THE DISCIPLINE BRAZILIAN PROBLEMS STUDY (EPB) IN THE FEDERAL UNIVERSITY OF VIÇOSA (UFV): IN FOCUS OF THE EDUCATIONAL PROJECT OF THE CIVIL-MILITARY REGIME FOR BRAZILIAN UNIVESRSITIES
}

\begin{abstract}
In the context of the intensification of the forces of the civil-military regime and the intensification of population control strategies, in 1969 the discipline Study of Brazilian Problems (EPB) was created. Directed to higher education, it was an ideological instrument of the educational project of the military to confront the student movement and the supposed threats of communism. In this sense, the text aims to contribute to the discussions about the project to socialize the interests of the military regime in Brazilian universities, based on documentary research, contextualizing the EPB discipline at the Federal University of Viçosa (MG), through official sources, such as the catalogs of disciplines of the institution and of the minutes and documents of the meetings of higher collegiate councils of the period of validity of the discipline (1969/1993). With regard to the research in its locus, one can conclude, due to the organization of the BPS courses and their validity, the full adherence to the institution. Another point that deserves to be highlighted was the realization of the courses of EPB merging students of the University College and undergraduate and postgraduate courses, even such practice not being prescribed by law. What gives us the strength to think that there was not a didactic-pedagogical effort, to suppose by the differences between the levels of schooling, but rather the commitment in transmitting the message of the military governments to the Brazilian students.
\end{abstract}

Keywords: Brazilian Problems Study (EPB); Civil-military regime; National Security Doctrine (DSN); Federal University of Viçosa (UFV).

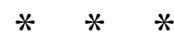

\section{Introdução}

A partir da segunda metade do século XX, tanto na Europa 
Ocidental quanto no Brasil, são identificados regimes autoritários que atingiram os direitos mais básicos dos cidadãos, inclusive o direito à vida. A partir da história recente produzida por esses regimes, percebemos a reorganização pretendida pelo Estado, que visava à democracia, aos direitos universais do homem e à valorização da segurança nacional, contrária à ameaça comunista.

Entretanto, no Brasil, mesmo após um período mais autoritário com o Estado Novo varguista (1937-1945), as bases democráticas não foram fortes o suficiente para solidificar e implementar uma noção alargada de garantia de direitos, propiciando assim, segundo Rolemberg (2009), condições para o fortalecimento do discurso golpista, o que culminou no golpe civil-militar em si. Tendo como pressuposto a teoria de Bourdieu (2009), entendemos que a democracia não era um habitus no Brasil, portanto não conseguiu superar os ditos perigos dos inimigos do Estado, da família e da Igreja, que aqui serão discutidos a posteriori, propondo o fortalecimento das políticas de segurança nacional e da criação de disciplinas escolares para a socialização das ideias do regime. Essa contradição marcou um longo período da história da Educação brasileira: o medo do comunismo e de sua pretensa opressão nos levou a um período de intensa e perversa repressão no espaço escolar, depois do Golpe de 1964.

Nesse contexto, cabe ressaltar que o conceito de habitus é entendido como uma importante categoria na teoria de Bourdieu (2002), que busca a compreensão entre as interseções do indivíduo e da sociedade, principalmente no que se refere às condições objetivas e às estruturas sociais pertencentes aos sujeitos, o que explica uma predisposição específica para as suas ações.

O ano de 1968 é considerado o início do auge do regime militar brasileiro. No âmbito nacional se deu a homologação do Ato Institucional $\mathrm{n}^{\circ} 5$ (AI-5), que arregimentou, entre outras medidas, a garantia das perdas de mandatos políticos, as intervenções ordenadas pelo presidente em estados e municípios e a suspensão de proteções constitucionais, como o habeas corpus. Neste contexto, a tortura, 
prática comumente utilizada pelo Estado, ganha um caráter mais legítimo e institucionalizado.

Em âmbito internacional destacaram-se as manifestações civis francesas, envolvendo estudantes, trabalhadores e partidos políticos, contrários às ações violentas do governo diante das demandas de reformas no setor educacional.

Nos Estados Unidos, as insatisfações populares vão de encontro aos conflitos bélicos no Vietnã (1955-1975) e à participação do governo norte-americano, representante do bloco capitalista, na Guerra Fria (1946-1991). O movimento hippie (1960-1970), de contracultura, também contribui para o agravo das críticas. É lá também que ocorrem os assassinatos do líder do movimento de direitos da população negra, Martin Luther King Jr. (1968), e do senador e candidato à presidência da república, Robert Kennedy (1968).

É nesse contexto que, em 1969, a disciplina Estudo dos Problemas Brasileiros (EPB) é posta como obrigatória para o seguimento do ensino superior. Com proposta análoga à Educação Moral e Cívica (EMC) e à Organização Social e Política do Brasil (OSPB), a disciplina EPB deveria formar e fomentar os jovens nos contributos da segurança e do desenvolvimento nacionais, prezando pelo preparo moral e cívico, espiritual e ético, e nacionalista e defensor da democracia (BOMENY, 1981). É importante ressaltar que junto com o regimento legal que estabeleceu a obrigatoriedade da disciplina de EMC, Decreto no 869/1969, criou-se o Conselho Nacional de Moral e Civismo (CNMC), responsável pela elaboração de currículos, programas e metodologias para o ensino da disciplina.

Vale destacar que, conforme exposto por Oliveira (1982), existiam tanto entidades civis como religiosas e associações femininas que reivindicavam a presença da EMC no currículo escolar, antes de 1969. Isto oferece indícios para refletir sobre o apoio e os interesses em um regime civil-militar no Brasil, presentes antes mesmo da sua efetivação, em 1964.

Cabe ressaltar que a disciplina OSPB é anterior ao regime civil- 
militar, uma vez que sua criação se deu em 1962. Entretanto, ela foi rapidamente absorvida pelos militares e, em 1969, transferida para o ciclo colegial, como reforço programático à EMC, que era prescrita no primário e no ginasial. O tripé Deus-Pátria-Família e a Doutrina de Segurança Nacional (DSN) compunham o conteúdo programático da disciplina.

É importante destacar que o tripé Deus-Pátria-Família não tem seu primeiro registro no contexto da ditadura civil-militar brasileira, mas, sim, mais de três décadas antes, quando foi organizada a Ação Integralista Brasileira (AIB). Movimento de cunho partidário, posicionado politicamente à extrema-direita, com inspiração clara no fascismo, teve como seu principal expoente Plínio Salgado. Sob a égide da integração da família como instituição núcleo da sociedade, amparada pelo Estado, forte e centralizador, a integralização e o fortalecimento do Brasil aconteceriam.

Com uma tendência ao liberalismo econômico, os integralistas tiveram a simpatia do governo Getúlio Vargas, em sua primeira aparição, devido ao entendimento nacionalista e autoritário. Mas, com o período do Estado Novo (1937-1945), Vargas impõe a repressão também ao integralismo, já que os partidos políticos estavam proibidos.

Cabe refletir também que, com o Golpe de 2016, que impôs o impeachment à Presidenta Dilma Rousseff, a volta do discurso de base fascista, como direcionamento de diversos segmentos políticos, expôs novamente as categorias Deus-Pátria-Família. Essas categorias mobilizaram bastante os discursos político-eleitorais e ganharam repercussão para o anúncio de políticas públicas. Entre essas propostas destacamos o Projeto Escola sem Partido.

Esses preceitos faziam parte do enfrentamento aos antagonistas ao regime, entre eles: a ideologia comunista, os movimentos de estudantes e trabalhadores e a suposta ameaça à moralidade cristã. É preocupante constatar que, mesmo após 50 anos do início de um período que marcou a história do País com a tortura e o medo, esses preceitos voltam a ser reivindicados nos campos político e 
educacional.

A partir deste contexto, é nosso objetivo refletir sobre o projeto de socialização político-ideológico presente na EPB e objetivado pelo Estado brasileiro. Neste artigo pretende-se discutir de forma mais localizada o caso da disciplina na Universidade Federal de Viçosa. Para isto, remontaremos aos documentos institucionais concernentes à organização da disciplina EPB. O recorte temporal amparado pelas fontes inicia em 1969, quando a disciplina é imposta como obrigatória, e termina em 1993, quando sua oferta é revogada.

A caracterização da EMC como projeto político-pedagógico do regime militar, instrumento do autoritarismo bem definido, alimentou uma série de trabalhos que adensaram a compreensão da disciplina escolar, da história do Brasil e dos destinatários dessas políticas de socialização: as crianças e os jovens. No entanto, trabalhos sobre a EPB são menos desenvolvidos, podendo ser citados os de Cunha (2010; 2012). É interessante ressaltar que, em um recorte desse período coevo do século XX, mesmo com as idiossincrasias históricas, outros regimes militaristas e autoritários utilizaram-se de grande intervenção na Educação para divulgação de seus projetos políticos, como: Portugal salarizarista, Espanha franquista, Argentina peronista, Itália fascista de Mussolini e Alemanha nazista de Hitler. No Brasil, além do período do regime civil-militar, a Era Vargas, principalmente no Estado Novo, também fez uso da mesma estratégia.

Como supracitado, a EPB cumpriria o papel da EMC no ensino superior. Para essa função, em ambas as disciplinas ficam claras as disposições que coadunam em um mesmo sentido do projeto políticopedagógico do regime, com balizas de autoritarismo e conservadorismo. É importante destacar que a implantação da disciplina foi alvo de resistência por parte dos destinatários almejados pelos militares: os estudantes, principalmente aqueles envolvidos com o movimento estudantil, como apontam as pesquisas de Cancian (2010).

Cancian afirma que a disciplina EPB configura-se como um 
instrumento sofisticado e distinto de repressão e vigia, uma vez que os métodos até então utilizados eram pouco eficazes para o controle desses estudantes e dos movimentos sociais. Vale salientar que, além da disciplina EPB, outras ações em sentidos próximos e direcionadas às universidades foram tomadas. Apesar de não ser o foco do presente estudo, um exemplo foi o Projeto Rondon. Desenvolvido na Universidade do Estado do Rio de Janeiro (UERJ), dois anos antes da implantação da EPB, tornou-se o programa de extensão mais conhecido da época e figurou como uma estratégia de controle da participação política dos universitários e do ideal de desenvolvimento nacional do Estado.

Como parte do regime, a EPB ganhou apoio de setores da sociedade civil e de instituições que, conforme Motta (2014), incrementaram com demandas próprias o projeto político da disciplina. Assim, um viés liberal modernizador e o catolicismo reacionário e conservador foram basilares na estrutura da EPB e no combate dos inimigos imaginados: a doutrina comunista e o enfraquecimento da família, motor do desenvolvimento da nação. Para além das contribuições de setores e da sociedade civil, a DSN elaborada pela Escola Superior de Guerra (ESG) conferiu grande contribuição de fundamentação teórica, objetivando um projeto de socialização dos valores do regime.

Neste artigo, propõe-se apresentar reflexões sobre o projeto político-pedagógico da disciplina EPB de forma ampliada e, posteriormente, mais localizada na Universidade Federal de Viçosa. Assim, o termo socialização aqui é empregado no sentido de refletir sobre os ideários do regime para a sociedade, em especial aqueles direcionados ao segmento do ensino superior.

Destarte, para o alcance do objetivo proposto, pretende-se revisitar as questões da moral e do civismo brasileiros, em especial no contato com os campos das instituições militares e religiosas. Nesta perspectiva, o conceito de campo abordado aqui refere-se a Bourdieu (2004), cujo termo é representativo de um espaço autônomo, que é produto e produtor de regimentos (formulações simbólicas) criados, 
apropriados, disseminados e reconstruídos pelos próprios sujeitos participantes do campo. São esses modelos que formam e conformam o campo e as ações dos indivíduos nele inseridos.

Assim, a partir de Sepúlveda (2010), um modelo explicativo para a sobreposição das forças militar e religiosa no campo educacional, culminando até na criação de uma disciplina como a $\mathrm{EPB}$, deveu-se à fragilidade e à falta de autonomia desse campo.

Bourdieu (2004), neste caso, denomina heteronomia o campo menos forte, por conseguinte o menos autônomo, que sofre diretamente a influência de outros campos. Novamente é relevante refletir como nos dias atuais, a partir de novos arranjos, existe a permanência da sobreposição de valores de outros campos de forma incidente no espaço educacional.

Neste sentido, de acordo com Sepúlveda (2019), os campos mais fortes, portanto mais autônomos, continuam a exercer uma projeção sobre os campos menos autônomos. Assim, segundo o autor, o campo educacional brasileiro sempre se caracterizou por ser menos forte, $o$ que garantiu a projeção de interesses militares, religiosos e privados, ora juntos, ora separados, a depender do momento histórico.

Para além disto, a DSN é o ponto de contato para a caracterização da EPB. Ambas as análises globais permitirão explicitar os pontos de toque entre elas e propor conexões com o contexto da Universidade Federal de Viçosa.

\section{A disciplina EPB como instrumento planeado para o Regime Militar}

Quando se trata de disciplinas que tenham como objeto a moral e o civismo, de modo geral, são evocadas disciplinas como a EMC e a OSPB, que remetem claramente ao regime militar, uma vez que sua formatação e sua arregimentação são coevas ao período e ao governo. Entretanto, desde a Proclamação da República, a preocupação com a formação de cidadãos, amparada pelo lema da bandeira brasileira 
"Ordem e Progresso", já era uma questão. E para isto, a Educação seria um bom instrumento formativo, à medida que esses valores morais, cristãos e cívicos eram imiscuídos nos currículos. Apesar das transformações nos distintos âmbitos da sociedade desde o final do século XIX, a projeção dos ideários religioso e militar continuou a sobrepor o campo educacional e, principalmente, o político. De forma diretamente proporcional, quanto maior o cenário de desarmonia social, maior a reivindicação pela educação moral e cívica. Cabe ressaltar que, de acordo com Cunha (2009), a valorização de aspectos nacionais e do civismo é uma influência positivista, notadamente marcada durante a Primeira República (1889-1930), que foi resgatada em distintos momentos, incluindo o da ditadura civil-militar.

Chalhoub (1986) destaca que em momentos de instabilidade e crise, ou de um estreitamento do regime político, a Educação é utilizada como instrumento a serviço do projeto político-pedagógico do governo. Um exemplo disto foi que no Estado Novo, na Era Vargas, por meio dos livros didáticos, as representações imagéticas e musicais conferiam protagonismo à moral e ao civismo, pertinentes à formação do cidadão e à ordem nacional, como pontos gerais da discussão. Além disso, verificava-se a abordagem de questões mais próprias àquele contexto: a formação do trabalhador, o combate à vadiagem $\mathrm{e}$ ao malandro e o controle dos sindicatos trabalhistas. É neste escopo que disciplinas como a EMC e a EPB são revisitadas e regimentadas entre o interstício de 1969 e 1971, no decurso do regime civil-militar.

Assim, no decorrer do século XX, a educação da moral e do civismo figurou em várias faces no ambiente escolar, desde práticas educativas até sua instituição como disciplina obrigatória. Em cada prisma, foi moldada a responder questões próprias daquela sociedade sob a égide religiosa e militar. Assim, disciplinas como a EMC terão relações com os interesses cristãos e oficiais do Exército, de acordo com o seu período de vigência e os pontos considerados de destaque para o contexto. Apesar de quando da criação da disciplina EMC, a disposição legal a considerar como aconfessional, seu conteúdo era prenhe da doutrina católica (CUNHA, 2010). Prova disto é o Decreto- 
Lei no 869/1969, que retrata a defesa da inspiração de Deus e a preservação dos valores espirituais.

Embora o ensino moral e cívico não fosse uma exclusividade do regime militar brasileiro, é nesse período, em virtude das cores locais de maior repressão ao movimento estudantil, por exemplo, que tal educação foi mais imbricada com a doutrina governamental. Logo, é com o Decreto-Lei no 869/1969 que a EMC e, depois com o seu molde para a universidade, a EPB foram instituídas, alcançando todos os níveis de ensino, e compromissadas com o projeto político do regime militar. E é com os antagonismos do regime que a EPB se inseriu na composição de uma frente de combate, conforme disposto no Decreto:

a) a defesa do princípio democrático, através da preservação do espírito religioso, da dignidade da pessoa humana e do amor à liberdade com responsabilidade, sob a inspiração de Deus;

b) a preservação, o fortalecimento e a projeção dos valores espirituais e éticos da nacionalidade;

c) o fortalecimento da unidade nacional e do sentimento de solidariedade humana;

d) o culto à pátria, aos seus símbolos, tradições, instituições e grandes vultos de sua história;

e) o aprimoramento do caráter, com apoio na moral, na dedicação à família e à comunidade;

f) a compreensão dos direitos e deveres dos brasileiros e o conhecimento da organização sócio-político-econômica do país;

g) o preparo do cidadão para o exercício das atividades cívicas, com fundamento na moral, no patriotismo e na ação construtiva visando ao bem comum;

h) o culto da obediência à lei, da fidelidade ao trabalho e da interação na comunidade (BRASIL, 1969).

Portanto, é com o desenvolvimento dos fundamentos democrático, religioso e civil, conforme o regime presente na disciplina EPB, que as ameaças do comunismo e do esfacelamento da instituição familiar seriam enfrentadas. Imbuídos desse sentido, a preparação dos jovens para o desenvolvimento do País dava-se a partir da sua conscientização sobre a situação do Estado e dos postos 
de trabalho. A juventude deveria estar preparada moral e politicamente, pela EPB, para poder fomentar e participar do progresso brasileiro.

É interessante observar que a ideia de liberdade, posta pelo regime, era antagônica às ideologias de esquerda e ao comunismo e que o seu par perfeito era a responsabilidade, indicando a melhor forma para se vivê-la. O mesmo pode ser constatado no binômio democracia-cidadania, no entendimento do regime. A cidadania pensada no Decreto-Lei no 869/1969, como compreensão de direitos e deveres e como exercício para a formação cívica, só seria possível em uma sociedade democrática, patriótica e moralizada. No entanto, percebe-se que essas noções estreitas sobre cidadania e democracia, presentes na disciplina EPB, por exemplo, legitimam e reforçam um cerceamento de formação e de participação dos estudantes universitários, permitindo clarividência na constatação do caráter instrumental da disciplina para o regime.

Assim, cabe ressaltar também que a caracterização de conceitos como democracia e cidadania, por exemplo, além de explícita congruência com os valores preconizados pelo regime, é construída em relação de oposição ao que se negava e/ou lutava contra: o comunismo e os regimes de esquerda.

Outro exemplo disso é a referência a Deus. A partir da definição de comunista entendido como ateu, a religião católica, concebida como universal e como majoritária, foi também instrumental, devido aos seus valores e princípios, para o controle social. A moral, tão ressaltada pelo regime, não seria a mesma sem a tradição religiosa. Entretanto, cabe também refletir, para além da atualidade de determinados contextos, sobre a ambiguidade inscrita: um estado laico, que faz uso instrumental da religião e que até invoca seus símbolos e seu Deus para a proteção das cartas magnas.

Se o Decreto-Lei no 869/1969 explicita os valores nacionais e os inimigos do Brasil, o Parecer no 94/1971, do Conselho Federal de Educação (CFE), que normatiza os currículos das disciplinas EMC e $\mathrm{EPB}$, apresentava clara referência à DSN, que reforçou os ideários do 
regime e o caráter serviente aos seus interesses. Estes pontos serão enfocados na seção a seguir.

\section{A DSN e a ESG no projeto político-pedagógico da EPB}

Nos anos finais da década de 1940, a ESG é criada no Brasil. Ela representou um marco para o campo militar e tinha como missão ser um centro de estudos sobre a Política Nacional e desenvolver todo o planejamento da Segurança Nacional (SEPÚLVEDA, 2010). Por se tratar de um aparelho ideológico militar que, após o Golpe de 1964, serviu também ao regime, as pesquisas realizadas pela ESG, bem como seus cursos e as palestras ministradas, a exemplo do Curso Superior de Guerra (CSG), foram instrumentos importantes para divulgar a todos os preceitos preconizados pelo Estado. Do ponto de vista aqui enfocado, a disciplina EPB, apoiada na DSN da ESG, criada pela Associação dos Diplomados da Escola Superior de Guerra (ADESG), foi um elo entre o regime e as universidades.

A DSN era um constructo teórico dos militares em relação ao desenvolvimento do Brasil, preservando o conservadorismo dos valores cristãos e prenhe de diretrizes contra o comunismo e as demandas dos partidos de esquerda, como a reforma agrária e os direitos dos trabalhadores. É necessário destacar que, em âmbito global, o contexto do período é marcado pela Guerra Fria e que a posição do governo brasileiro era de alinhamento com os Estados Unidos. Assim, sob as bandeiras de desenvolvimento e segurança nacionais, a DSN, de forma bastante hábil, como aponta Sepúlveda (2010), articulava os valores almejados pelos militares, escamoteados como princípios fundamentais para o avanço econômico brasileiro. Portanto, os valores postos como relativos à DSN eram, na verdade, os mesmos do setor religioso, que reafirmava seus princípios de moralidade e da família; do político-militar, pelo controle e cerceamento exercido; e da classe média alta, composta por empresários, que asseguravam para distante de si e de seus negócios 
as supostas consequências de um comunismo deturpado e perigoso.

É a partir da DSN e de seus seguimentos criadores e representativos que se identifica a sólida base ideológica para a instauração e manutenção do regime militar. Neste sentido, percebese a relação pari passu da DSN com os objetivos e conteúdos curriculares da disciplina EPB. Nos estudos de Camargo (1979), Borges (2009) e Santos (2010), fica nítido o cruzamento entre os dispositivos da DSN e da disciplina EPB. Os pilares da DSN, notadamente marcados pelo combate ao comunismo e pela manutenção da ordem nacional, estavam na EPB a partir dos parâmetros de: objetivos, poder, estratégia e segurança nacional. Todos os objetivos eram interligados entre si e garantidores da soberania e do progresso brasileiros, segundo os militares, e, sem exceção, estavam presentes no plano curricular da disciplina.

Refletindo que a ESG foi criada em 1949, em um contexto pósSegunda Guerra Mundial (1937-1945) e início da Guerra Fria (19461991), seus comandantes já estavam imbuídos dos ideais contrários à doutrina do comunismo. Somado a isto, anos depois, com o advento da Revolução Cubana de 1959, que integrou Cuba ao bloco socialista, a reorganização dos movimentos estudantil e operário e, a posteriori, a derrota dos Estados Unidos na Guerra do Vietnã e os movimentos hippie e de contracultura, o sinal de alerta para o fortalecimento do comunismo foi acionado pelo governo americano. Neste contexto, houve no Brasil uma reformulação da DSN, com espaço mais destacado para a moral, em prol de preparar os jovens para combater a ameaça à Segurança Nacional (OLIVEIRA, 1982). Nesse mesmo sentido, as disciplinas EMC e EPB tornaram-se obrigatórias, a fim de garantir que os jovens, considerados como essenciais para a sobrevivência da Nação, não fossem seduzidos pelo comunismo e pudessem lutar para a defesa do País.

Os marcos legais das disciplinas EMC e EPB foram o DecretoLei no 869/1969, que as tornou disciplina e prática educativa obrigatória, o Decreto no 68.065/1971, que regulamentou o DecretoLei no 869/1969, e o Parecer no 94/1971, do CFE, que normatizou os 
aspectos de ensino e de conteúdo das disciplinas. O Decreto no 68.065/1971 determinou a carga horária da disciplina e a quantidade de disciplinas necessárias para o desenvolvimento do conteúdo. O CFE dispôs os conteúdos da EPB em seis unidades temáticas, quais sejam:

- Unidade I - Panorama Geral da Realidade Brasileira;

- Unidade II - Problemas Morfológicos;

- Unidade III - Problemas de Desenvolvimento

Econômico;

- Unidade IV - Problemas Socioeconômicos;

- Unidade V - Problemas Políticos;

- Unidade VI - Segurança Nacional (BRASIL, 1971a).

Em breve arrazoado das unidades, encontra-se na primeira as disposições geopolíticas, a formação do povo brasileiro, as instituições sociais e as relações dos cidadãos na sociedade. Na segunda unidade, os três poderes, a democracia no Brasil e as estruturas social, política e econômica foram os pontos destacados.

A terceira unidade tinha por foco a discussão econômica, tratando de temas como trabalho, indústria, comércio, políticas monetárias, previdência social, transportes, energia, disparidades de desenvolvimento entre as regiões e reforma agrária.

$\mathrm{Na}$ quarta unidade, os eixos abordados foram os direitos à habitação, à saúde e à Educação, juntamente com as questões urbanas, o papel da ciência, da tecnologia e do Exército para o desenvolvimento econômico do País.

Questões de ciências políticas e de filosofia, que permeavam os pilares da DSN, e de ocupação do território, somadas às relações brasileiras com organismos internacionais como a Organização das Nações Unidas (ONU) e a Organização dos Estados Americanos (OEA), foram as temáticas apresentadas na quinta unidade.

Na última unidade, o Conselho de Segurança Nacional, o Estado Maior das Forças Armadas e a ESG foram os objetivos gerais, uma vez que a segurança interna e externa do Brasil era o tema principal. Todos os conteúdos das unidades mencionadas eram considerados 
como problemas brasileiros, os quais, a partir do estudo, deveriam ser conhecidos e repensados para o desenvolvimento nacional.

De acordo com Cunha (2012), as duas últimas unidades, que tratavam mais diretamente de conteúdos da DSN, foram responsáveis por configurar um caráter mais doutrinário à EPB. Essa relação entre a DSN e a EPB já está clara no Decreto no 869/1969 e ratificada no Parecer no 94/1971, pois parte do texto que se refere ao ensino da EMC e da EPB vem da ADESG. Segundo Lemos (2011), essa Associação foi pioneira na configuração da EMC relacionada à Segurança Nacional, uma vez que os pedidos de inclusão do ensino de moral e cívica no currículo escolar não eram novidade. Portanto, quando se propõe um paralelismo do civismo e da moralidade atrelado às questões de segurança interna e externa do País, as disciplinas que encabeçam essas propostas são instrumentos de controle e cerceamento das universidades e do movimento estudantil, em prol do ideário do regime.

A partir das diretrizes formuladas pela ADESG, conduzidas para o Gabinete da Presidência da República pelo então Ministro da Guerra, General Costa e Silva, havia a necessidade de revisão da Lei de Diretrizes e Bases da Educação (LDB), de 1961, pois seu texto era muito neutro e moroso na formação da juventude, não a capacitando para o enfrentamento ao comunismo e para a defesa nacional. Nas leituras de Bomeny (1981) e de Cunha (2009), ficam claras as duas principais ações requeridas pelo Exército para a disciplina EMC e, posteriormente, para a EPB: a primeira é uma barreira protetiva contra as ideologias de esquerda, sem amparo aos jovens brasileiros, e a segunda é a sólida disseminação dos ideais do regime para a formação dos jovens, conforme prescrito pela DSN.

\section{A disciplina EPB nos currículos da Universidade Federal de Viçosa}

A pesquisa retratada neste texto foi realizada no Arquivo 
Central e Histórico, vinculado ao Departamento de História da Universidade Federal de Viçosa (UFV). As fontes primárias utilizadas foram os Catálogos de Graduação, que reúnem todas as disciplinas oferecidas pelos institutos/departamentos da instituição, com também trazem alguns dados da administração e dos professores. Os primeiros Catálogos de Graduação datam de 1970, o que confere uma impossibilidade de refletir sobre o período anterior com esse tipo de fonte. Foram incorporados ao rol das fontes um relatório e um plano de curso da disciplina, de 1972.

Por meio da pesquisa, identificamos que a disciplina EPB foi ministrada pelo Departamento de Pedagogia durante toda década de 1970. Essa unidade compunha a Escola Superior de Estudos Domésticos, que, em 1971, tornou-se o Departamento de Educação, unidade independente, seguindo os moldes da Reforma Universitária de 1968. A partir da década de 1980, a matéria passa a ser ofertada pelo Departamento de Administração de Empresas e Ciências Econômicas. Nesse período, os catálogos nos oportunizam uma maior descrição da disciplina.

Neste sentido, observa-se a seguinte ementa: “ADE 188 - EPB I (1 crédito teórico - anteriormente EDU 128). Problemas Morfológicos. Problemas de Desenvolvimento Econômico. Problemas Socioeconômicos.” (CATÁLOGO DE GRADUAÇÃO, 1980). Já para a disciplina EPB II, o prescrito era: “ADE 189 - EPB II (1 crédito teórico - anteriormente EDU 129). Programa Geral da Realidade Brasileira. Problemas Políticos. Segurança Nacional". (CATÁlOGO DE GRADUAÇÃO, 1980).

Com base nos dados dos documentos visitados, constatou-se que a disciplina EPB ocupava uma carga horária de 15 horas durante o semestre letivo. Ela era ofertada aos recém-ingressantes da instituição, em forma de palestras aos sábados, para evitar conflito de horário com as demais disciplinas dos cursos.

Outro ponto que merece destaque é o fato da EPB estar presente entre as disciplinas ofertadas nos programas de pós-graduação. Apesar das normativas federais não tratarem da obrigatoriedade da 
disciplina nos cursos de mestrado e doutorado, a UFV prescreve a disciplina aos estudantes da pós-graduação, de forma análoga ao que era feito nos cursos de graduação e no Colégio Universitário.

Entre as fontes mapeadas na pesquisa, encontramos uma comunicação interna (CI), do ano de 1972, da Secretária do Conselho de Pós-Graduação endereçada ao professor coordenador do Curso de Zootecnia, na qual ela solicita a matrícula dos estudantes da pósgraduação na disciplina PED 328 - Estudo dos Problemas Brasileiros. A mensagem contida no documento é um indício que nos permite afirmar sobre o caráter local da disciplina na UFV. Esse caráter é de enquadramento nos rigores da DSN, não apenas aos estudantes do ensino de segundo grau e da graduação, mas também, para além do prescrito, dos estudantes da pós-graduação.

No Catálogo de Graduação de 1992 e 1993, a disciplina já não é mais ofertada, uma vez que a Lei Federal no 8.663/1993 em seu artigo 1o. revoga o Decreto-Lei no 869/1969 e no artigo 2o indica que a carga horária da disciplina EPB deverá ser incorporada a outras disciplinas da área de Ciências Humanas e Sociais (BRASIL, 1993).

No caso do Colégio Universitário (Coluni), de acordo com Hollerbach (2016), de 1966 a 1974, a EMC era matéria obrigatória aos estudantes de segundo grau, e era composta de uma carga horária de 1 hora semanal. Já entre 1975 e 1980, era a OSPB que estava presente no currículo, inserida nas discussões dos Estudos Sociais que, a partir de 1979, ofertava separadamente as disciplinas de História e Geografia.

Hollerbach (2016) destaca que os estudantes do Coluni cursavam a disciplina EPB com os estudantes da graduação e com os estudantes de cursos técnicos de nível médio ofertados pela universidade. Segundo o relatório do professor responsável pela disciplina, em 1972, alunos do Coluni e do curso técnico de Administração do Lar, oferecido à época pela Escola Superior de Ciências Domésticas, compartilhavam a disciplina numa mesma turma.

A autora aponta outras incongruências no que diz respeito à 
presença da disciplina no currículo do Colégio Universitário. Mesmo com o Decreto-Lei no 869/1969, que tratava da obrigatoriedade do ensino de EMC nos estabelecimentos de ensino de grau médio, o Colégio Universitário só atendeu a essa exigência até 1974 (HOLLERBACH, 2016).

Outro ponto a ser destacado é que, independentemente da nomenclatura da disciplina, a saber: EMC, EPB ou OSPB, a estrutura das atividades era em forma de palestra, feita por convidados, como professores e representantes de instituições ligadas à agricultura e representantes de empresas prestadoras de serviços públicos e órgãos de defesa, proteção e segurança, como comandantes da Polícia Militar mineira e do Batalhão do Corpo de Bombeiros daquela região.

A conferência de encerramento foi realizada pelo governador do estado, Rondon Pacheco.

No Plano de Curso de 1971, as temáticas preconizadas pelas palestras, foram:

- O Homem Brasileiro;

- Instituições Sociais, Polícias e Econômicas;

- O Comportamento Social: Estratificação, Mobilidade e Adaptação Social;

- Análise do Sistema Econômico Brasileiro;

- Características da Democracia no Brasil;

- Estrutura dos Poderes Constituídos no Brasil;

- Riqueza Nacional do Solo e Subsolo;

- A Amazônia e seus Problemas;

- A Política Florestal Brasileira;

- O Nordeste e seus Problemas;

- Os Transportes e a Economia Nacional;

- O Desenvolvimento Agrícola e Pecuário;

- A Reforma Agrária;

- Comércio Interno e Internacional;

- O Problema Energético e o Desenvolvimento Industrial;

- Disparidades Regionais, Desequilíbrio Socioeconômico e

Organismos Regionais;

- Planejamento Econômico, Política Monetária, Creditícia e

Fiscal de Mercado de

- O Problema Habitacional Brasileiro;

Capitais;

- O Problema Sanitário, no Brasil;

- O Problema Educacional Brasileiro;

- Política Nacional;

- Política Externa e Organismos Políticos Internacionais; 
- A Segurança Nacional (HOLLERBACH, 2016, p. 104).

A autora destaca que nem todos os temas foram proferidos nas palestras, uma vez que, em virtude da dinamicidade e das questões coevas às disciplinas, algumas alterações ocorreram. Destarte, podese concluir que a Universidade Federal de Viçosa estabeleceu arranjos que extrapolavam os prescritos legais para a oferta das disciplinas. Neste sentido, notamos duas vias principais: ora por um excesso de rigor na oferta das disciplinas, ora por agrupamentos e oferecimentos conforme a disponibilidade e a organização que não estavam preconizadas nas diretrizes legais.

\section{Palavras finais: considerações sobre o projeto político-pedagógico da EPB e a Universidade Federal de Viçosa}

No percurso do texto, constata-se que a EPB nasceu para articular as propostas de formação segundo a DSN no ensino superior. Assim, juntamente com a DSN, havia ainda uma perspectiva formativa para o mercado de trabalho e o desenvolvimento do País, por meio da modernização. Esse processo fomentaria o desenvolvimento econômico, por um lado, e garantiria a segurança nacional, por outro. Portanto, a EPB, neste quadro, manteria a prevalência dos interesses dos militares e prepararia os estudantes, cientes dos problemas brasileiros, para o desenvolvimento e a segurança nacional.

Por outro prisma, os ideários do regime militar continuavam sendo contemplados com a disciplina, por exemplo, valores como a democracia e a liberdade política e econômica, mesmo que de forma questionável. A perspectiva conservadora também foi enfocada, uma vez que, neste aspecto, a dupla temática prevaleceu: o enaltecimento do tripé Deus-Pátria-Família e o combate ao perigo vermelho, à destruição da religião católica e aos fatores de abalo à família e à 
moralidade. É neste sentido que Motta (2014) afirma que a EPB atendeu tanto ao impulso liberal-modernizante quanto ao autoritário-conservador do regime.

Destarte, como elemento para diversificar a campanha de controle dos jovens pelos militares e de combater a suposta ameaça do comunismo, a disciplina EPB, junto com a DSN, trabalhou para o fortalecimento dos interesses do Estado e de sua sobreposição, utilizando o campo educacional como instrumento de sensibilização e arrebatamento dos jovens para o imaginário do regime.

No que tange à pesquisa em seu locus, pode-se concluir, com base na organização dos cursos de EPB e de sua vigência, a plena aderência na instituição. Outro ponto que merece destaque foi a realização dos cursos de EPB mesclando alunos do Colégio Universitário e dos cursos de graduação e pós-graduação, mesmo não sendo essa prática prescrita na lei. Esse arranjo nos confere embasamento para pensar que o objetivo preconizado não era um esforço didático-pedagógico, a supor pelas diferenças entre os níveis de escolarização dos estudantes envolvidos, mas, sim, a transmissão da mensagem dos governos militares aos estudantes brasileiros para manter a ordem e o progresso da nação.

Por fim, renasce o temor ao percebermos que os princípios que moviam esses interesses ressurgem em propostas como o Projeto Escola sem Partido. Portanto, conclui-se que a luta por uma Educação pública, laica, gratuita, de qualidade e socialmente referenciada ainda é uma batalha por realizar, visto que os monstros do passado se agigantam sobre nós.

\section{Referências}

BOMENY, H. M. B. Paraíso tropical: a ideologia do civismo na TVE do Maranhão. Rio de Janeiro: Achiamé, 1981. 
BORGES, N. A doutrina de Segurança Nacional e os governos militares. In: FERREIRA, J.; DELGADO, L. A. N. (org.). O Brasil republicano - o tempo da ditadura: regime militar e movimentos sociais em fins do século XX. 3. ed. Rio de Janeiro: Civilização Brasileira, 2009. v. 4.

BOURDIEU, P. A escola conservadora: As desigualdades frente à escola e à cultura. In: NOGUEIRA, M. A.; CATANI, A. (Org.). Escritos e educação. Petrópolis: Vozes, 2002, p. 39-64.

BOURDIEU, P. Os usos sociais da ciência: por uma sociologia clínica do campo científico. São Paulo: Editora da UNESP, 2004.

BOURDIEU, P. A Economia das Trocas simbólicas. São Paulo: Perspectiva, 2009.

BRASIL. Decreto-Lei no 869, de 12 de setembro de 1969. Dispõe sobre a inclusão da Educação Moral e Cívica como disciplina obrigatória, nas escolas de todos os graus e modalidades, dos sistemas de ensino no País, e dá outras providências.

BRASIL. Decreto no 68.065, de 14 de janeiro de 1971a. Regulamenta o Decreto-lei np 869, de 12 de setembro de 1969, que dispõe sobre a inclusão da Educação Moral e Cívica como disciplina obrigatória, nas escolas de todos os graus e modalidades dos sistemas de ensino no País, e dá outras providências.

BRASIL. Lei no 5.692 , de 11 de agosto de 1971b. Fixa as Diretrizes e Bases para o ensino de 1o e $2^{\circ}$ graus e dá outras providências.

BRASIL. Parecer $n^{\circ}$ 94/71, 4 de fevereiro de 1971c, do CFE. In: AGUIAR, J. M. (Org.). CFE - Pareceres básicos; Reforma - ensino de 1o e 2o. graus. Brasília: Mai Editora, 1975, v. 1. Disponível em: http://www.histedbr.fe.unicamp.br/navegando/fontes_escritas/7_ Gov_ Militar/parecer\%20n.\%2094-1971sobre\%20emc.pdf. Acesso em: 11 jul. 2019.

BRASIL. Lei no 8.663 de 14 de junho de 1993. Revoga o Decreto-Lei no 869, de 12 de dezembro de 1969, e dá outras providências.

CAMARGO, E. J. C. Estudo de problemas brasileiros. Rio de Janeiro: Biblioteca do Exército, 1979.

CANCIAN, R. Movimento estudantil e repressão política: ato público na Pontifícia Universidade Católica de São Paulo (1977) e o destino de uma geração de estudantes. São Carlos: EDUFSCar, 2010.

CHALHOUB, S. Trabalho, lar e botequim. São Paulo: Brasiliense, 1986.

CUNHA, L. A. A laicidade em xeque: religião, moral e civismo na educação brasileira -1931/97. 2009. Disponível em: http://www. 
nepp-dh.ufrj.br/ole/textos_equipe2.html. Acesso em: 01 abr. 2019. CUNHA, L. A. Ambiguidade ideológica na universidade: os estudos de problemas brasileiros. Revista do Centro de Filosofia e Ciências Humanas/CFCH, Rio de Janeiro, ano 1, n. 1, 2010.

CUNHA, L. A. Os estudos de problemas brasileiros na UFRJ: aproximações institucionais. Revista Contemporânea de Educação, Rio de Janeiro, v. 7, n. 13, 2012.

HOLLERBACH, J. D. G. O Colégio Universitário (COLUNI) da Universidade Federal de Viçosa (1965-1981): formar para universidade e garantir a qualidade. Tese (Doutorado em Educação) - Universidade Federal de São Carlos, 2016.

LEMOS, K.S.C. A normatização da Educação Moral e Cívica (19611993). 2011. Dissertação (Mestrado). Faculdade de Educação. Universidade Federal do Rio de Janeiro, Rio de Janeiro.

MOTTA, R. P. S. As universidades e o regime militar: cultura política brasileira e modernização autoritária. Rio de Janeiro: Zahar, 2014.

OLIVEIRA, M. A. B. Política e educação no Brasil: a implantação da obrigatoriedade da Educação Moral e Cívica no ensino brasileiro em 1969. 1982. Dissertação (Mestrado em Educação) - Faculdade de Educação. Universidade de São Paulo, São Paulo, 1982.

ROLEMBERG, D. Esquerdas Revolucionárias e luta Armada. In: $O$ Brasil Republicano - O Tempo da Ditadura: regime militar e movimentos sociais em fins do século XX. FERREIRA, J.; DELGADO, L. de A. N. (Org). Rio de Janeiro: Civilização Brasileira, 2009.

SANTOS, E. R. Poder e dominação no Brasil: a Escola Superior de Guerra (1974-1989). Porto Alegre: Sulina; Novo Hamburgo: Feevale, 2010.

SEPÚlVEDA, J. A. M. O papel da Escola Superior de Guerra na projeção do campo militar sobre o campo educacional. 2010. Tese (Doutorado em Educação) - Faculdade de Educação. Universidade Federal do Rio de Janeiro, Rio de Janeiro, 2010.

UNIVERSIDADE FEDERAL DE VIÇOSA. Catálogo de Graduação, 1972.

. Catálogo de Graduação, 1980.

. Relatório e Plano de Curso da disciplina de EPB, 1972.

Recebido em 25 de agosto de 2019.

Aprovado em 25 de novembro de 2019. 